Check for updates

Cite this: RSC Adv., 2017, 7, 40015

Received 21st June 2017 Accepted 24th July 2017

DOI: 10.1039/c7ra06933b

rsc.li/rsc-advances

\section{Sumalactones A-D, four new curvularin-type macrolides from a marine deep sea fungus Penicillium Sumatrense $\uparrow$}

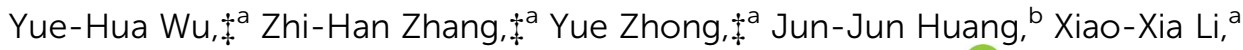 \\ Jin-Yan Jiang, ${ }^{a}$ Yin-Yue Deng, ${ }^{\text {ac }}$ Lian-Hui Zhang ${ }^{a}$ and Fei He iD *a
}

Sumalactones A-D (1-4), four new curvularin-type macrolides, together with two known analogues, curvularin (5) and dehydrocurvularin (6), were isolated from Penicillium Sumatrense, a marine fungus isolated from deep-sea sediments. Sumalactones C (3) and D (4) are unprecedented curvularin-type macrolides bearing a rare 11 -membered macrolide skeleton. Their structures were elucidated on the basis of intensive spectroscopic analysis. The absolute configurations of compounds 1-4 were determined by CD spectra and modified Mosher's method. Compound 6 showed significant inhibition activity towards LPS-induced nitric oxide production in RAW 264.7 macrophages with $I_{50}$ value of $0.91 \mu \mathrm{M}$.

\section{Introduction}

Among fungal macrolides, resorcinylic acid lactones (RALs) and dihydroxyphenylacetic acid lactones (DALs) belong to a unique family of naturally occurring homologous macrolides, which are characterized by possessing a macrolide core structure fused to a resorcinol aromatic ring. ${ }^{1}$ Curvularins, featuring a substituted resorcinol fragment fused to the $\beta, \gamma$-positions of the macrocyclic lactone ring, are produced by a number of fungal species mainly from the genera Aspergillus, ${ }^{2}$ Alternaria, ${ }^{3}$ Astragalus, ${ }^{4}$ Curvularia ${ }^{5}$ Cochliobolus $^{6}{ }^{6}$ and Penicillium ${ }^{7}$ with diverse biological activities. They are biogenetically derived from the polyketide synthase pathways in bacterial and fungi, and have brought great interest and challenges for total synthesis and biosynthesis studies. ${ }^{8}$

In the course of our ongoing research on new bioactive secondary metabolites from marine fungi, ${ }^{9}$ Penicillium sumatrense was isolated from a deep-sea sediment sample $(-2500 \mathrm{~m}$ depth) of the Indian Ocean, which resulted in the isolation of four new curvularin derivatives, sumalactones A-D (1-4) with 10- or 11- or 12-membered macrolide skeletons, as well as two

${ }^{a}$ Integrative Microbiology Research Centre, College of Agriculture, South China Agricultural University, Guangzhou 510642, People's Republic of China. E-mail: hefei@scsio.ac.cn; Fax: +86-20-85288229; Tel: +86-20-85288229

${ }^{b}$ Pharmaceutical Research Center, School of Pharmacology, Guangzhou Medical University, Guangzhou 510182, People's Republic of China

${ }^{c}$ Guangdong Innovative and Entrepreneurial Research Team of Sociomicrobiology Basic Science and Frontier Technology, South China Agricultural University, Guangzhou 510642, People's Republic of China

$\dagger$ Electronic supplementary information (ESI) available: Spectroscopic data of 1-4, preparation of $(S)$ - and (R)-MTPA esters of $\mathbf{1}$ and 3, and the 1D and 2D NMR spectra of 1-4. See DOI: 10.1039/c7ra06933b

\$ These authors have contributed equally to this work. known compounds curvularin $(5)^{10}$ and dehydrocurvularin (6). ${ }^{11}$ Compounds 3 and $\mathbf{4}$ with 11-membered macrolides skeleton are considered rare in nature and haven't been reported before. All the compounds were evaluated for their inhibitory effect on the production of nitric oxide (NO) induced by lipopolysaccharide (LPS) in RAW 264.7 macrophages. Herein we report the isolation, structure elucidation, and biological activities of these compounds (Fig. 1).

\section{Results and discussion}

Sumalactone A (1) gave an HRESIMS ion peak at $\mathrm{m} / \mathrm{z} 307.1197$ $[\mathrm{M}-\mathrm{H}]^{-}$, corresponding to the molecular formula $\mathrm{C}_{16} \mathrm{H}_{20} \mathrm{O}_{6}$, which required seven degrees of unsaturation. The UV spectrum showed absorption maxima at 204, 218, 269, and $297 \mathrm{~nm}$. The ${ }^{1} \mathrm{H}$ signals (Table 1 ) suggested a pair of meta-coupled aromatic protons at $\delta_{\mathrm{H}} 6.12(\mathrm{~d}, J=1.8 \mathrm{~Hz}, \mathrm{H}-4)$, and $6.24(\mathrm{~d}, J=2.0 \mathrm{~Hz}, \mathrm{H}-$ 6) and one methyl group at $\delta_{\mathrm{H}} 1.12\left(3 \mathrm{H}, \mathrm{d}, J=6.2 \mathrm{~Hz}, \mathrm{CH}_{3}-16\right)$.
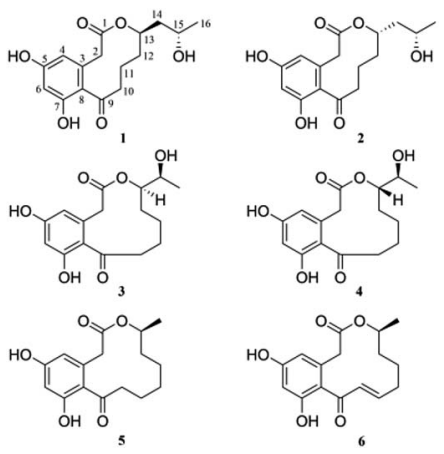

Fig. 1 Chemical structures of 1-6 
Table $1{ }^{1} \mathrm{H}$ NMR $(500 \mathrm{MHz})$ and ${ }^{13} \mathrm{C}$ NMR $(125 \mathrm{MHz})$ spectroscopic data of $1-4$ in $\mathrm{CD}_{3} \mathrm{OD}(\delta$ in ppm, $\mathrm{J}$ in $\mathrm{Hz})$

\begin{tabular}{|c|c|c|c|c|c|c|c|c|}
\hline \multirow[b]{2}{*}{ No. } & \multicolumn{2}{|l|}{1} & \multicolumn{2}{|l|}{2} & \multicolumn{2}{|l|}{3} & \multicolumn{2}{|l|}{4} \\
\hline & $\delta_{\mathrm{C}}$ & $\delta_{\mathrm{H}}$ & $\delta_{\mathrm{C}}$ & $\delta_{\mathrm{H}}$ & $\delta_{\mathrm{C}}$ & $\delta_{\mathrm{H}}$ & $\delta_{\mathrm{C}}$ & $\delta_{\mathrm{H}}$ \\
\hline 1 & 171.8 & & 172.7 & & 172.4 & & 172.5 & \\
\hline 2 & 41.3 & $\begin{array}{l}3.44, \mathrm{~d}(18.3) \\
3.96, \mathrm{~d}(18.4)\end{array}$ & 41.3 & $\begin{array}{l}3.49, \mathrm{~d}(18.5) \\
3.98, \mathrm{~d}(18.4)\end{array}$ & 41.1 & $\begin{array}{l}3.46, \mathrm{~d}(17.2) \\
4.14, \mathrm{~d}(17.1)\end{array}$ & 41.1 & $\begin{array}{l}3.50, \mathrm{~d}(17.1) \\
4.11, \mathrm{~d}(17.2)\end{array}$ \\
\hline 3 & 136.3 & & 136.2 & & 136.3 & & 136.3 & \\
\hline 4 & 110.6 & $6.12, \mathrm{~d}(1.8)$ & 110.6 & $6.13, \mathrm{~d}(1.6)$ & 111.5 & $6.16, \mathrm{~d}(2.2)$ & 111.7 & $6.17, \mathrm{~d}(2.2)$ \\
\hline 5 & 161.0 & & 161.0 & & 160.9 & & 160.9 & \\
\hline 6 & 102.4 & $6.24, \mathrm{~d}(2.0)$ & 102.4 & $6.24, \mathrm{~d}(2.0)$ & 102.6 & $6.25, \mathrm{~d}(2.2)$ & 102.6 & $6.24, \mathrm{~d}(2.2)$ \\
\hline 7 & 158.8 & & 158.9 & & 158.8 & & 158.7 & \\
\hline 8 & 122.6 & & 122.6 & & 122.0 & & 122.0 & \\
\hline 9 & 211.6 & & 211.5 & & 209.8 & & 209.9 & \\
\hline 10 & 46.7 & $\begin{array}{l}2.70, \mathrm{~m} \\
3.06, \mathrm{~m}\end{array}$ & 46.6 & $\begin{array}{l}2.70, \text { ddd }(2.1,7.7,15.9) \\
3.06, \text { ddd }(2.2,10.5,15.4)\end{array}$ & 41.7 & $\begin{array}{l}2.87, \text { ddd }(3.4,6.1,17.5) \\
3.17, \text { ddd }(3.1,11.6,17.4)\end{array}$ & 41.8 & $\begin{array}{l}2.86, \text { ddd }(3.3,6.0,17.3) \\
3.19, \text { ddd }(3.2,11.6,17.3)\end{array}$ \\
\hline 11 & 23.4 & $1.87,2 \mathrm{H}, \mathrm{m}$ & 23.4 & $1.87,2 \mathrm{H}$, overlapped & 23.9 & $\begin{array}{l}\text { 1.47, overlapped } \\
1.89, \mathrm{~m}\end{array}$ & 23.9 & $\begin{array}{l}\text { 1.47, overlapped } \\
1.89, \mathrm{~m}\end{array}$ \\
\hline 12 & 35.4 & $\begin{array}{l}\text { 1.47, overlapped } \\
1.95, \mathrm{~m}\end{array}$ & 36.3 & $\begin{array}{l}1.47, \text { overlapped } \\
1.87 \text {, overlapped }\end{array}$ & 22.0 & $\begin{array}{l}1.23, \mathrm{~m} \\
1.66, \mathrm{~m}\end{array}$ & 22.1 & $\begin{array}{l}1.23, \mathrm{~m} \\
1.67, \text { overlapped }\end{array}$ \\
\hline 13 & 76.3 & $4.91, \mathrm{~m}$ & 76.3 & $4.90, \mathrm{~m}$ & 26.1 & $\begin{array}{l}\text { 1.47, overlapped } \\
1.75, \mathrm{~m}\end{array}$ & 26.3 & $\begin{array}{l}1.47, \text { overlapped } \\
1.67, \text { overlapped }\end{array}$ \\
\hline 14 & 45.3 & $\begin{array}{l}\text { 1.47, overlapped } \\
1.70, \text { ddd }(6.6,7.5,14.1)\end{array}$ & 45.9 & $\begin{array}{l}\text { 1.47, overlapped } \\
1.56 \text {, ddd }(3.8,7.9,14.2)\end{array}$ & 79.8 & 4.75, ddd $(3.3,5.1,10.5)$ & 79.9 & 4.78, ddd $(2.7,6.0,10.2)$ \\
\hline 15 & 65.5 & $3.69, \mathrm{~m}$ & 65.1 & $3.65, \mathrm{~m}$ & 69.4 & $3.63, \mathrm{dq}(5.3,6.3)$ & 69.2 & $3.62, \mathrm{p}(6.4)$ \\
\hline 16 & 23.9 & $1.12, \mathrm{~d}(6.2)$ & 23.6 & $1.09, \mathrm{~d}(6.2)$ & 18.7 & $0.98, \mathrm{~d}(6.4)$ & 18.9 & $1.02, \mathrm{~d}(6.5)$ \\
\hline
\end{tabular}

Analysis of ${ }^{13} \mathrm{C}$ NMR and DEPT spectra data (Table 1) together with the HSQC data indicated the presence of six sp ${ }^{2}$ quaternary carbons including one ketone carbonyl carbon $\left(\delta_{\mathrm{C}} 211.6\right)$ and one ester carbonyl carbon $\left(\delta_{\mathrm{C}} 171.8\right)$, two $\mathrm{sp}^{2}$ methine carbons $\left(\delta_{\mathrm{C}} 110.6\right.$ and 102.4), two $\mathrm{sp}^{3}$ oxygenated methine carbons $\left(\delta_{\mathrm{C}} 76.3\right.$ and 65.5$)$, five $\mathrm{sp}^{3}$ methylene carbons, and one methyl carbon $\left(\delta_{\mathrm{C}} 23.9\right)$. The ${ }^{1} \mathrm{H}$ and ${ }^{13} \mathrm{C}$ NMR data were nearly identical to curvularin (5), ${ }^{10}$ except that C-13 methylene carbon in 5 was replaced by an oxygenated methine carbon $\left(\delta_{\mathrm{C}} 76.3\right)$ in 1 , which was confirmed by the ${ }^{1} \mathrm{H}^{-1} \mathrm{H}$ COSY correlations between $\mathrm{H}-13$ $\left(\delta_{\mathrm{H}} 4.91\right)$ and $\mathrm{H}_{2}-12\left(\delta_{\mathrm{H}} 1.47\right.$ and 1.95). In addition, the key HMBC correlation from $\mathrm{H}-13\left(\delta_{\mathrm{H}} 4.91\right)$ to ester carbonyl carbon C-1 $\left(\delta_{\mathrm{C}}\right.$ 171.8) indicated the location of the 10-membered lactone between C-1 and C-13. Thus, the planar structure of 1 was established (Fig. 2). In order to determine the absolute configuration of $\mathrm{OH}$ group at $\mathrm{C}-15$, the modified Mosher's method was applied. ${ }^{12}$ When reacted with $(R)$ - and $(S)$-MTPA chloride, 1 gave the corresponding $(S)$ - and $(R)$-MTPA esters, respectively. The observed chemical shift differences $\Delta \delta_{\mathrm{H}(S-R)}$ (Fig. 3) clearly defined the $S$ configuration at C-15. The absolute configuration of C-13 was determined by CD spectrum (Fig. 4). The positive Cotton effect at approximately $265 \mathrm{~nm}$ and negative

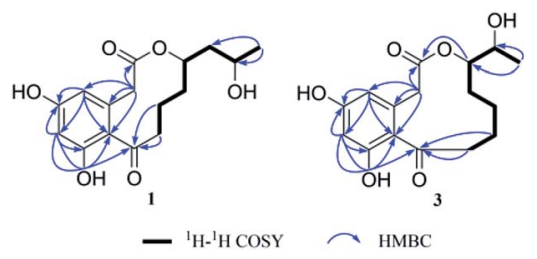

Fig. 2 Key ${ }^{1} \mathrm{H}-{ }^{1} \mathrm{H}$ COSY and $\mathrm{HMBC}$ correlations of 1 and 3.
Cotton effect at $316 \mathrm{~nm}$ of 1 suggested the $R$ configuration at C-13, comparing to that of xestodecalactone A with opposite sign. ${ }^{c c, 13}$ Therefore, the absolute configuration of 1 was established as $13 R, 15 S$.

Sumalactone B (2) was isolated as a yellow oil and it was determined to be $\mathrm{C}_{16} \mathrm{H}_{20} \mathrm{O}_{6}$ on the basis of negative HRESIMS, indicating that 2 is isomeric to 1 . Indeed, analysis of the NMR data indicated that compound $\mathbf{2}$ had the same planer structure as 1 . Considering that the only difference observed between 2 and 1 was the completely opposite CD curves (Fig. 4), we suggest that 2 is epimeric at C-13 relative to compound $\mathbf{1}$. Consequently, the absolute configuration of 2 was assigned as $13 S, 15 S$.
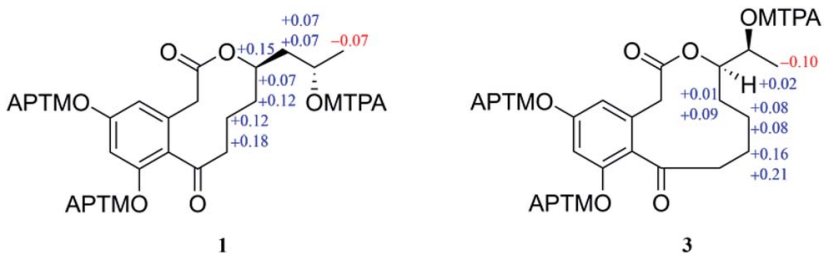

Fig. $3 \Delta \delta\left(\delta_{S}-\delta_{R}\right)$ values (in ppm) for the MTPA esters of 1 and 3.
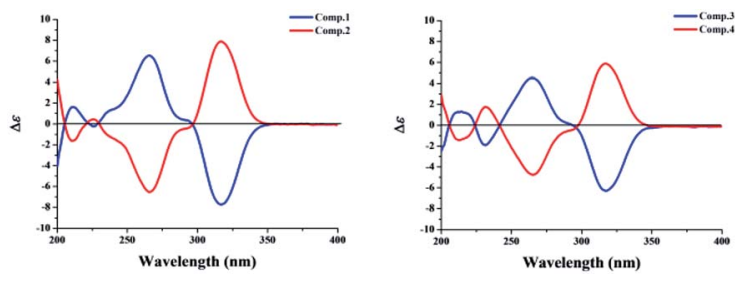

Fig. 4 CD spectra of $1-4$. 
Sumalactone C (3) was obtained as a yellow oil, for which the molecular formula was assigned as $\mathrm{C}_{16} \mathrm{H}_{20} \mathrm{O}_{6}$ by HRESIMS, from a $[\mathrm{M}-\mathrm{H}]^{-}$ion at 307.1191 (calc. 307.1182). The UV absorptions together with ${ }^{1} \mathrm{H}$ and ${ }^{13} \mathrm{C}$ NMR data indicated the curvularintype macrolide skeleton similar to that of compound 1 . The ${ }^{1} \mathrm{H}-{ }^{1} \mathrm{H}$ COSY correlations between $\mathrm{H}_{2}-13 / \mathrm{H}-14 / \mathrm{H}-15 / \mathrm{H}_{3}-16$, and HMBC correlation from $\mathrm{H}-14\left(\delta_{\mathrm{H}} 4.75\right)$ to $\mathrm{C}-1\left(\delta_{\mathrm{C}} 172.4\right)$, confirmed the 11-membered macrolide in compound 3 , which was rare in nature and was first example of oxygenation at C-14 in curvularin skeleton. The absolute configuration at C-14 was assigned to be $R$ because of the almost identical CD spectrum to that of $\mathbf{1}$ (Fig. 4). The $\mathrm{OH}$ group at $\mathrm{C}-15$ was determined as $S$ by the modified Mosher's method (Fig. 3). Therefore, the absolute configuration of 3 was established as $14 R, 15 S$.

Sumalactone D (4) was attributed the molecular formula $\mathrm{C}_{16} \mathrm{H}_{20} \mathrm{O}_{6}$ from its HRESIMS at $m / z \quad 307.1014\left([\mathrm{M}-\mathrm{H}]^{-}\right.$ 307.1014, calc. 307.1182). On analysis of its ${ }^{1} \mathrm{H}$ and ${ }^{13} \mathrm{C} \mathrm{NMR}$ spectra, similar features to that of 3 were evident, but with an opposite CD curve (Fig. 4). Therefore, the absolute configuration at C-14 was assigned as $S$. Thus, the absolute configuration of 4 was assigned as $14 S, 15 S$.

In addition to compounds $\mathbf{1 - 4}$, the known curvularin $(5)^{10}$ and dehydrocurvularin (6) ${ }^{\mathbf{1 1}}$ were also isolated and identified from the fungal strain P. sumatrense MCCC 3A00612. All isolated compounds were tested for inhibitory activities against LPS-induced NO production in RAW 264.7 macrophages. As the results, only compound 6 showed significant NO production inhibitory activity with $\mathrm{IC}_{50}$ of $0.91 \pm 0.03 \mu \mathrm{M}$, which was comparable to that of the positive control $\mathrm{L}-\mathrm{NMMA}\left(\mathrm{IC}_{50}\right.$ of $41.91 \pm 1.27 \mu \mathrm{M})$. The cell viability measured by the MTS assay showed that compound $\mathbf{6}$ had no significant cytotoxicity to the RAW 264.7 cells at the effective concentration for the inhibition of NO production.

\section{Experimental section}

\section{General experimental procedures}

Optical rotations were measured on an MCP 300 polarimeter, and UV spectra were measured on a U-2910 spectrometer. IR spectra were measured on an Affinity-1 FT-IR spectrometer. The CD spectra were recorded in $\mathrm{MeOH}$ using a Chirascan spectropolarimeter at room temperature. HRESIMS spectra were obtained on Waters Synapt G2 TOF mass spectrometer. The NMR data were acquired with a Bruker AV 500 NMR spectrometer using solvent signals $\left(\mathrm{CD}_{3} \mathrm{OD}: \delta_{\mathrm{H}} 3.30 / \delta_{\mathrm{C}} 49.0\right)$ as standards. Column chromatography (CC) was carried out on Sephadex LH-20 (Pharmacia, USA), and ODS (60-80 $\mu \mathrm{m}$, YMC). TLC was performed on silica gel plate (SGF254, 0.2 $\mathrm{mm}$, Merck, Germany). Analytical and semi-preparative HPLC were performed on an Agilent HPLC system equipped with a G1311B pump, a G1329B automated sample injector, a G1316A column compartment, and a G1315D diode array detector using a Phenomenex Kinetex C18 column $(4.6 \times 250$ $\mathrm{mm}, 5 \mu \mathrm{m})$, a Waters T3 C18 column $(4.6 \times 250 \mathrm{~mm}, 5 \mu \mathrm{m})$ and a Phemomenex Kinetex C18 column $(10.0 \times 250 \mathrm{~mm}, 5$ $\mu \mathrm{m})$.

\section{Fungus material}

The fungus $P$. sumatrense MCCC 3A00612 was isolated from deep-sea sediments collected from the Indian Ocean. The strain was identified by Dr Zongze Shao, and a voucher specimen (P. sumatrense MCCC 3A00612) has been deposited in the Marine Culture Collection of China.

\section{Extraction and isolation}

The fresh mycelia of $P$. sumatrense were grown on PDA medium at $28{ }^{\circ} \mathrm{C}$ for 4 days. Agar plugs were cut into small pieces and were selected to inoculate 10 Erlenmeyer flasks $(500 \mathrm{~mL})$ each containing $200 \mathrm{~mL}$ of PDB. The seed cultures were incubated at $28{ }^{\circ} \mathrm{C}$ on a rotary shaker $(150 \mathrm{rpm})$ for 5 days and were then inoculated into $60 \times 500 \mathrm{~mL}$ conical flasks on rice solid medium ( $80 \mathrm{~g}$ rice, $0.36 \mathrm{~g}$ sea salt, and $120 \mathrm{~mL}$ filtered water) for 30 days at $28{ }^{\circ} \mathrm{C}$. The fermented cultures were extracted with $70 \%$ acetone/water, and evaporated under reduced pressure to afford an aqueous solution, which was then extracted three times with EtOAc and afforded the EtOAc extract (10.4 g). The EtOAc extract $(10.4 \mathrm{~g})$ was fractionated by silica gel column chromatography (CC) eluting with $\mathrm{CHCl}_{3}-\mathrm{MeOH}(100: 0,95: 5$, $98: 2,9: 1,8: 2,1: 1$, and $0: 100, \mathrm{v} / \mathrm{v}$ ) to afford seven fractions (J1-J7). Fraction J5 $(877.8 \mathrm{mg})$ was further subjected to Sephadex LH-20 CC using $\mathrm{CHCl}_{3}-\mathrm{MeOH}(1: 1, \mathrm{v} / \mathrm{v})$ to afford four subfractions (J5-1 to J5-4). Subfraction J5-3 (374.0 mg) was separated on a ODS column with a gradient of $\mathrm{MeOH}-\mathrm{H}_{2} \mathrm{O}$ $(10: 90,30: 70,50: 50,70: 30$, and $100: 0, \mathrm{v} / \mathrm{v})$ to give three portions (J5-3-1 to J5-3-3). J5-3-1 (167.2 mg) was separated on semi-preparative HPLC using $\mathrm{CH}_{3} \mathrm{CN}-\mathrm{H}_{2} \mathrm{O}(15: 85, \mathrm{v} / \mathrm{v})$ to give five portions (J5-3-1-1 to J5-3-1-5). J5-3-1-1 (9.4 mg) was purified on semi-preparative HPLC by using $\mathrm{MeOH}-\mathrm{H}_{2} \mathrm{O}(30: 70, \mathrm{v} / \mathrm{v})$ to yield 1 (7.3 mg). J5-3-1-2 (9.6 mg) was purified on semipreparative HPLC by using $\mathrm{CH}_{3} \mathrm{CN}-\mathrm{H}_{2} \mathrm{O}(22: 78$, v/v) to yield 2 (4.3 mg). J5-3-1-4 (7.4 mg) was purified on semi-preparative HPLC by using $\mathrm{MeOH}-\mathrm{H}_{2} \mathrm{O}(30: 70, \mathrm{v} / \mathrm{v})$ to yield 3 (2.9 mg). J53-1-5 (10.6 mg) was purified on semi-preparative HPLC by using $\mathrm{MeOH}-\mathrm{H}_{2} \mathrm{O}$ (30: 70, v/v) to yield 4 (2.3 mg). J5-3-2 (112.0 $\mathrm{mg}$ ) was purified on semi-preparative HPLC by using $\mathrm{MeOH}-$ $\mathrm{H}_{2} \mathrm{O}(55: 45, \mathrm{v} / \mathrm{v})$ to yield $5(8.5 \mathrm{mg})$. Fraction J3 $(4.0 \mathrm{~g})$ was subjected to a ODS column with a gradient of $\mathrm{MeOH}-\mathrm{H}_{2} \mathrm{O}$ $(30: 70,50: 50,70: 30$, and $100: 0, v / v)$ to give four subfractions (J3-1 to J3-4). Subfraction J3-2 (519.6 mg) was further separated by ODS CC eluting with $\mathrm{MeOH}-\mathrm{H}_{2} \mathrm{O}(50: 50, \mathrm{v} / \mathrm{v})$ to afford four portions (J3-2-1 to J3-2-4). J3-2-2 (21.0 mg) was purified on semi-preparative $\mathrm{HPLC}$ by using $\mathrm{MeOH}-\mathrm{H}_{2} \mathrm{O}$ $(50: 50, \mathrm{v} / \mathrm{v})$ to yield $6(6.8 \mathrm{mg})$.

Sumalactone A (1). Yellow oil (MeOH); $[\alpha]_{\mathrm{D}}^{25}-124.0$ (c 0.1, $\mathrm{MeOH})$; UV (MeOH) $\lambda_{\text {max }}(\log \varepsilon) 204$ (4.13), 218 (4.08), 269 (3.76), 297 (3.68) nm; CD (0.81 mM, MeOH) $\lambda_{\max }(\Delta \varepsilon) 211$ (1.61), 226 (-0.22), 266 (6.52), 317 (-7.72) nm; IR (MeOH) $\nu_{\max } 3194,2968$, 2938, 1715, 1663, 1607, 1589, 1472, 1339, 1267, 1161, 1136, 1024, 1007, 845, $669 \mathrm{~cm}^{-1}$; HRESIMS $m / z 307.1197[\mathrm{M}-\mathrm{H}]^{-}$ (calcd for $\mathrm{C}_{16} \mathrm{H}_{19} \mathrm{O}_{6}, 307.1182$ ); the ${ }^{1} \mathrm{H}$ and ${ }^{13} \mathrm{C}$ NMR data, see Table 1.

Sumalactone B (2). Yellow oil (MeOH); $[\alpha]_{\mathrm{D}}^{25}+86.1$ ( c 0.1 , $\mathrm{MeOH}) ; \mathrm{UV}(\mathrm{MeOH}) \lambda_{\max }(\log \varepsilon) 203$ (4.02), 218 (3.94), 268 (3.62), 
298 (3.55) nm; CD (0.81 mM, MeOH) $\lambda_{\max }(\Delta \varepsilon) 210(-1.61), 226$ (0.45), 266 (-6.54), 317 (7.89) nm; IR (MeOH) $\nu_{\max }$ 3167, 2967, 2932, 1705, 1661, 1605, 1589, 1404, 1339, 1252, 1161, 1089, 1024, 989, $845 \mathrm{~cm}^{-1}$; HRESIMS $m / z 307.1193[\mathrm{M}-\mathrm{H}]^{-}$(calcd for $\left.\mathrm{C}_{16} \mathrm{H}_{19} \mathrm{O}_{6}, 307.1182\right)$; the ${ }^{1} \mathrm{H}$ and ${ }^{13} \mathrm{C}$ NMR data, see Table 1.

Sumalactone C (3). Yellow oil $(\mathrm{MeOH}) ;[\alpha]_{\mathrm{D}}^{25}-41.6$ (c 0.1, $\mathrm{MeOH}) ; \mathrm{UV}(\mathrm{MeOH}) \lambda_{\max }(\log \varepsilon) 203$ (4.04), 219 (3.95), 268 (3.61), 297 (3.54) nm; CD (0.81 mM, MeOH) $\lambda_{\max }(\Delta \varepsilon) 214$ (1.30), 231 (-1.90), 265 (4.53), $318(-6.30) \mathrm{nm}$; IR $(\mathrm{MeOH}) \nu_{\max } 3256,2934$, $1703,1651,1607,1591,1462,1335,1261,1161,1088,1042$, 1013, 845, $665 \mathrm{~cm}^{-1}$; HRESIMS $m / z 307.1191[\mathrm{M}-\mathrm{H}]^{-}$(calcd for $\left.\mathrm{C}_{16} \mathrm{H}_{19} \mathrm{O}_{6}, 307.1182\right)$; the ${ }^{1} \mathrm{H}$ and ${ }^{13} \mathrm{C}$ NMR data, see Table 1.

Sumalactone D (4). Yellow oil (MeOH); $[\alpha]_{\mathrm{D}}^{25}+35.8(c 0.1$, $\mathrm{MeOH}) ; \mathrm{UV}(\mathrm{MeOH}) \lambda_{\max }(\log \varepsilon) 203$ (4.04), 219 (3.96), 268 (3.63), 298 (3.54) nm; CD (0.81 mM, MeOH) $\lambda_{\max }(\Delta \varepsilon) 213(-1.45), 231$ (1.76), 265 (-4.75), 317 (5.87) nm; IR (MeOH) $\nu_{\max } 3304,2943$, 1703, 1651, 1607, 1462, 1337, 1265, 1161, 1040, 993, $847 \mathrm{~cm}^{-1}$; HRESIMS $m / z \quad 307.1014[\mathrm{M}-\mathrm{H}]^{-}$(calcd for $\mathrm{C}_{16} \mathrm{H}_{19} \mathrm{O}_{6}$, 307.1182); the ${ }^{1} \mathrm{H}$ and ${ }^{13} \mathrm{C}$ NMR data, see Table 1.

Curvularin (5). $[\alpha]_{\mathrm{D}}^{25}-22.5(c \quad 0.1, \mathrm{MeOH})$; literature value $[\alpha]_{\mathrm{D}}^{25}-28.6$ ( $c$ 0.4, EtOH).

Dehydrocurvularin $(6) .[\alpha]_{\mathrm{D}}^{25}-45.6(c 0.1, \mathrm{MeOH})$; literature value $[\alpha]_{\mathrm{D}}^{25}-65.9(c 1.8, \mathrm{EtOH})$.

\section{NO production bioassay}

The murine macrophage cell line RAW 264.7 was obtained from Cell Bank of Chinese Academy of Sciences. RAW 264.7 cells were seeded in 96-well cell culture plates $\left(1.5 \times 10^{5}\right.$ cells per well $)$ and treated with serial dilutions of the compounds with a maximum concentration of $25 \mu \mathrm{M}$ in triplicate, followed by stimulation with $1 \mu \mathrm{g} \mathrm{mL} \mathrm{m}^{-1}$ LPS (Sigma, St. Louis, MO, USA) for $18 \mathrm{~h}$. NO production in the supernatant was assessed by Griess reagents (Reagent A \& Reagent B, respectively, Sigma). The absorbance at $570 \mathrm{~nm}$ was measured with a microplate reader (Thermo, Waltham, MA, USA). $\mathrm{N}^{\mathrm{G}}$-methyl-L-arginine acetate salt (L-NMMA, Sigma), a well-known nitric oxide synthase (NOS) inhibitor, was used as a positive control. ${ }^{14}$ The viability of RAW 264.7 cells was evaluated by the MTS assay simultaneously to exclude the interference of the cytotoxicity of the test compounds.

\section{Conclusions}

In summary, six curvularin-type macrolides belonging to DALs group $^{15}$ were isolated from $P$. sumatrense MCCC 3A00612, including four new ones. The curvularins are octaketides composed of a 12-membered macrolide skeleton attached to a 3,5-dihydroxyphenylacetic acid. Compounds 1-4 are the new curvularin-type macrolides with 10- or 11-membered macrolide skeleton, among them, compounds $\mathbf{3}$ and $\mathbf{4}$ are the first macrolides with 11-membered macrolide skeleton. Interestingly, compounds 1-4 were isolated as epimers at the lactone carbon. Although the configuration at the lactone carbon is obviously variable among the DALs including the (-)-(15S)-curvularin (compound 5) and (+)-(15R)-curvularin series ${ }^{5}$ but they were isolated from different sources. However, epimers at the non- lactone carbon including (+)-(11S,15R)-11-hydroxycurvularin and $(+)-(11 R, 15 R)-11$-hydroxycurvularin, ${ }^{5}$ as well as $(-)-(11 R, 15 S)-11$-hydroxycurvularin and (-)-(11S,15S)-11hydroxycurvularin ${ }^{\mathbf{1 6}}$ were isolated from same sources. Therefore, the lactone formation does not change the absolute configuration of the lactone carbon, which is established upon generating the secondary hydroxyl group. Different positions of lactone cyclization would produce different ring sizes, which was certainly observed. In addition, compound 6 exhibited potent inhibitory effect on NO production when tested in vitro. High levels of NO are markers at the treatment of inflammatory disorders. Our results suggested that dehydrocurvularin (6) may be a potential candidate for further evaluation on the molecular mechanism of action on specific inflammatory disorders.

\section{Conflicts of interest}

There are no conflicts to declare.

\section{Acknowledgements}

This work was financially supported by the National Basic Research Program of China (2015CB150600), and the National Natural Science Foundation of China (31470236, 41206130), and the Pearl River Nova Program of Guangzhou (201506010067). We thank Chuan-Rong Li and Ai-Jun Sun for assistance with CD and NMR measurement and Dr Zong-Ze Shao for fungal strain isolation and identification.

\section{References}

1 J. W. Blunt, B. R. Copp, R. A. Keyzers, M. H. G. Munro and M. R. Prinsep, Nat. Prod. Rep., 2012, 29, 144-222.

2 O. Caputo and F. Viola, Planta Med., 1977, 31, 31-32.

3 D. J. Robeson, G. A. Strobel and R. N. Strange, J. Nat. Prod., 1985, 48, 139-141.

4 B. P. Bashyal, W. M. K. Wijeratne, J. Tillotson, A. E. Arnold, E. Chapman and A. A. L. Gunatilaka, J. Nat. Prod., 2017, 80, 427-433.

5 H. Greve, P. J. Schupp, E. Eguereva, S. Kehraus, G. Kelter, A. Maier, H. H. Fiebig and G. M. König, Eur. J. Org. Chem., 2008, 2008, 5085-5092.

6 E. L. Ghisalberti and C. Y. Rowland, J. Nat. Prod., 1993, 56, 2175-2177.

7 (a) C. J. Barrow, J. Nat. Prod., 1997, 60, 1023-1025; (b) L. H. Meng, X. M. Li, C. T. Lv, C. S. Li, G. M. Xu, C. G. Huang and B. G. Wang, J. Nat. Prod., 2013, 76, 21452149; (c) R. A. Edrada, M. Heubes, G. Brauers, V. Wray, A. Berg, U. Gräfe, M. Wohlfarth, J. Mühlbacher, K. Schaumann, G. Bringmann and P. Proksch, J. Nat. Prod., 2002, 65, 1598-1604.

8 (a) H. Choe, T. T. Pham, J. Y. Lee, M. Latif, H. Park, Y. K. Kang and J. Lee, J. Org. Chem., 2016, 81, 2612-2617; (b) P. M. Tadross, S. C. Virgil and B. M. Stoltz, Org. Lett., 2010, 12, 1612-1614; (c) Y. Xu, T. Zhou, P. Espinosa-Artiles, Y. Tang, J. Zhan and I. Molnár, ACS Chem. Biol., 2014, 9, 
1119-1127; (d) Q. R. Liang, Y. Q. Sun, B. X. Yu, X. G. She and X. F. Pan, J. Org. Chem., 2007, 72, 9846-9849.

9 (a) F. He, J. Bao, X. Y. Zhang, Z. T. Tu, Y. M. Shi and S. H. Qi, J. Nat. Prod., 2013, 76, 1182-1186; (b) F. He, Z. Liu, J. Yang, P. Fu, J. Peng, W. M. Zhu and S. H. Qi, Tetrahedron Lett., 2012, 53, 2280-2283; (c) F. He, Z. Han, J. Peng, P. Y. Qian and S. H. Qi, Nat. Prod. Commun., 2013, 8, 329-332; (d) F. He, Y. L. Sun, K. S. Liu, X. Y. Zhang, P. Y. Qian, Y. F. Wang and S. H. Qi, J. Antibiot., 2012, 65, 109-111; (e) Z. Zhang, X. Min, J. Huang, Y. Zhong, Y. Wu, X. Li, Y. Deng, Z. Jiang, L. Zhang and F. He, Mar. Drugs, 2016, 14, 233.

10 E. L. Ghisalberti, D. C. R. Hockless, C. Y. Rowland and A. H. White, Aust. J. Chem., 1993, 46, 571-575.

11 A. Kobayashi, T. Hino, S. Yata, T. J. Itoh, H. Sato and K. Kawazu, Agric. Biol. Chem., 1988, 52, 3119-3123.

12 (a) T. Kusumi, Y. Fujita, I. Ohtani and H. Kakisawa, Tetrahedron Lett., 1991, 32, 2923-2926; (b) B. N. Su,
E. J. Park, Z. H. Mbwambo, B. D. Santarsiero, A. D. Mesecar, H. H. S. Fong, J. M. Pezzuto and A. D. Kinghorn, J. Nat. Prod., 2002, 65, 1278-1282.

13 (a) G. Bringmann, G. Lang, M. Michel and M. Heubes, Tetrahedron Lett., 2004, 45, 2829-2831; (b) T. Yoshino, F. $\mathrm{Ng}$ and S. J. Danishefsky, J. Am. Chem. Soc., 2006, 128, 14185-14191; (c) Q. Liang, J. Zhang, W. Quan, Y. Sun, X. She and X. Pan, J. Org. Chem., 2007, 72, 2694-2697.

14 D. W. Reif and S. A. Mccreedy, Arch. Biochem. Biophys., 1995, 320, 170-176.

15 (a) J. Xu, C. S. Jiang, Z. L. Zhang, W. Q. Ma and Y. W. Guo, Acta Pharmacol. Sin., 2014, 35, 316-330; (b) Y. Xu, T. Zhou, Z. Zhou, S. Su, S. A. Roberts, W. R. Montfort, J. Zhang, M. Chen, W. Zhang, M. Lin, J. Zhan and I. Molnár, Proc. Natl. Acad. Sci. U. S. A., 2013, 110, 5398-5498.

16 S. Lai, Y. Shizuri, S. Yamamura, K. Kawai, Y. Terada and H. Furukawa, Tetrahedron Lett., 1989, 30, 2241-2244. 